\title{
Accumulation of the Long Class of siRNA Is Associated with Resistance to Plum pox virus in a Transgenic Woody Perennial Plum Tree
}

\author{
Jean-Michel Hily, ${ }^{1,2}$ Ralph Scorza, ${ }^{1}$ Kevin Webb, ${ }^{1}$ and Michel Ravelonandro ${ }^{2}$ \\ ${ }^{1}$ USDA-ARS Appalachian Fruit Research Station, 2217 Wiltshire Rd., Kearneysville, WV 25430, U.S.A.; ${ }^{2}$ Unité Mixte de \\ Recherches, Génomique dévelopment du Pouvoir pathogène, INRA-Université Bordeaux Segalen/Bordeaux, BP 81, 33883 \\ Villenave d'Ornon, France
}

Submitted 3 December 2004. Accepted 5 April 2005.

\begin{abstract}
We investigated the hallmarks of posttranscription gene silencing (PTGS) in mature plants, embryos, and seedlings of the transgenic plum trees (Prunus sp.) that are resistant to Plum pox virus (PPV). We previously demonstrated that the transgene insert and resistance to PPV were mutually inherited in progeny of line $\mathrm{C5}$. We show here that $\mathrm{C5}$ constitutively produces a short (22 nt) and a long ( 25 to $26 \mathrm{nt}$ ) species of short interfering (si)RNA from embryo to mature plant in the absence of PPV inoculation. Unlike siRNA, methylation and transcription of the PPV-coat protein transgene were 're-set' following seed germination. Uninoculated transgenic susceptible clones did not display DNA methylation, nor did they produce detectable levels of siRNA. Upon infection, susceptible clones, transgenic or untransformed, did produce siRNA but only the short 22-nt species. These findings show that plum trees respond to virus infection by initiating PTGS-like mechanisms that involve the production of siRNA. We further suggest that high-level virus resistance in transgenic Prunus species requires the production of the long-size class of siRNA. The research adds new insights into PTGS silencing in woody perennial plant species.
\end{abstract}

Additional keyword: Prunus domestica.

RNA silencing, a process leading to the degradation of homologous mRNAs, has been widely observed in animals, plants, and fungi (Hannon 2002; Kooter at al. 1999; Matzke et al. 2001; Vaucheret et al., 2001; Wianny and Zernicka-Goetz 2000). The occurrence of a similar mechanism in widely different organisms indicates a conserved biological function of RNA silencing during evolution (Fire et al. 1998). It has been shown that RNA silencing is essential for proper plant and animal development. RNA silencing not only participates in the control and regulation of endogenous gene expression in developmental processes (Hutvagner and Zamore 2002; Llave et al 2002) but also serves as a component of the natural defense mechanism against transposable elements (Bennetzen 2000) or invading alien RNA, in particular viral RNA (Waterhouse et al. 2001). Key components of the RNA silencing pathway are siRNAs (Hamilton and Baulcombe 1999) that derive from

Corresponding author: R. Scorza; E-mail: rscorza@afrs.ars.usda.gov

This article is in the public domain and not copyrightable. It may be freely reprinted with customary crediting of the source. The American Phytopathological Society, 2005. double-stranded (ds)RNA specifically degraded by DICER, an Rnase III-like enzyme (Bernstein et al. 2001). These siRNAs are then loaded into a multisubunit endonuclease, the RNAinduced silencing complex (RISC) (Hammond et al. 2000), which scans the pool of messenger RNA. siRNA ensure that the entire target molecule (e.g., viral RNA) that shares sequence similarity with the dsRNA is specifically degraded (Elbashir et al. 2001). It has been demonstrated that siRNAs serve as primers to convert the target mRNA into dsRNA through cellular RNAdirected RNA polymerase priming (Lipardi et al. 2001). This process subsequently generates new siRNA. Thus, siRNAs are diagnostic for RNA silencing.

We have previously shown that plum (Prunus domestica L.), a woody perennial fruit tree, transformed with the coat protein (CP) of PPV exhibits characteristics of RNA silencing (termed posttranscriptional gene silencing [PTGS] in plants), including a high level of transgene transcription in the nucleus, a low level of mRNA in the cytoplasm, multicopy transgene insertions with repeated sequences and one or more aberrant copies, and transgene methylation (Scorza et al. 1994, 2001). This PTGS clone (designated C5) is highly resistant to PPV infection (Ravelonandro et al. 1997; Scorza et al. 2001), and this resistance is stable under field conditions (Hily et al 2004). We have also demonstrated that the transgene insert and PPV resistance are co-inherited in C5 progeny (Ravelonandro et al. 1998; Scorza et al. 1998).

In order to better characterize RNA silencing in woody perennial crops, we tracked hallmarks of gene silencing in embryos, young seedlings, and mature trees. We also addressed questions of whether Prunus species are naturally able to trigger a PTGS-like mechanism, which includes siRNA production, in response to PPV infection and whether different classes of siRNAs are involved in the resistant phenotype. To study the correlation of PTGS and siRNA production in a woody perennial crop, two parallel experiments were designed with three transgenic clones, including the resistant clone C5 and susceptible clones C3 and PT23. Clone PT23 contained only two marker genes, neomycin phosphotransferase II (NPTII) and $\beta$-glucuronidase (GUS), which were in common with clones $\mathrm{C} 3$ and $\mathrm{C} 5$. We used $P$. domestica cultivar Bluebyrd as an untransformed control. The first trial involved plants that were healthy, and the second trial tested plants that had been inoculated with PPV. We show that production of the two species of siRNAs was associated with the resistant PTGS phenotype. We also analyzed ungerminated embryos and young seedlings to investigate 're-setting' of PTGS as shown in an herbaceous system (Guo et al. 1999). We found that, 
while methylation and mRNA production in the PPV-resistant C5 clone were apparently re-set in embryos and young seedlings, siRNA production was detected in embryos, seedlings, and mature plants.

\section{RESULTS}

Constitutive production of siRNA in a resistant plum clone.

Total RNAs extracted from different transgenic clones were analyzed for the presence of siRNA with a sequence specific to the PPV CP gene (Scorza et al 1994). siRNAs of approximately $22 \mathrm{nt}$ and 25 to $26 \mathrm{nt}$ were detected in leaf extracts of healthy C5 leaves (Fig. 1A, lane 4). This indicated that C5 constitutively produces both siRNA species and that PPV inoculation is not required to induce silencing of the transgene in this particular clone. Constitutive PTGS in clone C5 was described by Scorza and associates (2001).

In contrast, no siRNA were detected in healthy PPV-sensitive transgenic plum C3, PT23, and untransformed 'Bluebyrd' (Fig. 1A, lanes 1, 2, and 3). While both C5 and C3 contained multicopy inserts (Fig. 1B), only C5 was silenced for the PPV $\mathrm{CP}$ transgene and produced siRNA, indicating that not only transgene copy number but other factors are involved in the induction of the silenced phenotype.

\section{DNA methylation status of the PPV CP transgene in seedlings at different developmental stages.}

Previous studies in an herbaceous system showed that PTGS is re-set after a meiotic cycle. Restoration of PTGS is generated either by a silenced nuclear gene or by an exogenous source such as virus replication, which can switch a homologous gene from an active to a silenced status (Guo et al. 1999). From previous work on $\mathrm{C} 5$, we know that the transgene insert and resistance to PPV are coinherited (Ravelonandro et al. 1998; Scorza et al. 1998). Scorza and associates (2001) also demonstrated that uninoculated C5 seedlings displayed specific DNA methylation of the PPV CP transgene. While this suggested that transgene methylation was meiotically stable, these studies were performed using leaves from one-year-old seedlings.

In order to further investigate the meiotic stability of PTGS in C5 seedlings, studies on DNA methylation and PPV CP transgene mRNA expression were conducted on different stages of seedling development, including embryos and mature plants. The procedure employed to assess DNA methylation was based on the study by Ingelbrecht and associates (1994) coupled with real-time quantitative polymerase chain reaction (PCR). The level of methylation, as indicated by amplifiable DNA at the 340 Sau3AI site, of leaves from mature C5 trees was approximately 10 times greater than that in DNA from C3 trees under the same conditions and at the same developmental stage (Fig. 2A). Conversely, only a low level of methylation was observed in DNA extracted from C5 embryos and from seedlings 2 weeks postgermination. DNA analyses showed that, at 1 month postgermination, the PPV CP gene in C5 seedlings was methylated at levels comparable to those in leaves of the C5 parent. DNA from seedlings and parental leaves appeared to be more highly methylated at position 340 than at the 660 site, as previously observed in samples collected from field tests (Hily et al. 2004). These results demonstrated that methylation of the PPV CP transgene at the sites evaluated was re-set following meiosis and then was reinitiated, in the absence of virus infection, between 2 and 4 weeks postgermination.

\section{siRNA and mRNA levels in early development stages} of uninoculated transgenic plants.

Clone C3 (Scorza et al. 1994) produced high levels of PPV CP mRNA throughout development (Fig. 2B). No SiRNA was detected in $\mathrm{C} 3$ embryos (Fig. 3, lane 4) at 2 and 4 weeks (data not shown) or in the mature clone (Fig. 1, lane 3). However two bands of siRNA appeared to be present in C5 embryos (Fig. 3, lane 5) and also in seedlings at 2 and 4 weeks postgermination (data not presented). Unlike siRNA, PPV CP transgene transcription appeared to be re-set following meiosis in C5. Embryos and samples collected 2 weeks postgermination displayed increased levels of PPV CP transcript, whereas leaves from 1-month-old seedlings expressed relatively low levels of PPV CP transcript, similar to that expressed by the parental tree (Fig. 2B).

Analyses of methylation and transcription of the PPV CP insert demonstrate that these processes are inversely related in C5.

\section{The effect of PPV inoculation}

on siRNA accumulation in Prunus sp.

siRNA production during virus infection was examined in leaf samples collected from inoculated plants. Transformed susceptible clone C3, clone PT23, which does not contain the
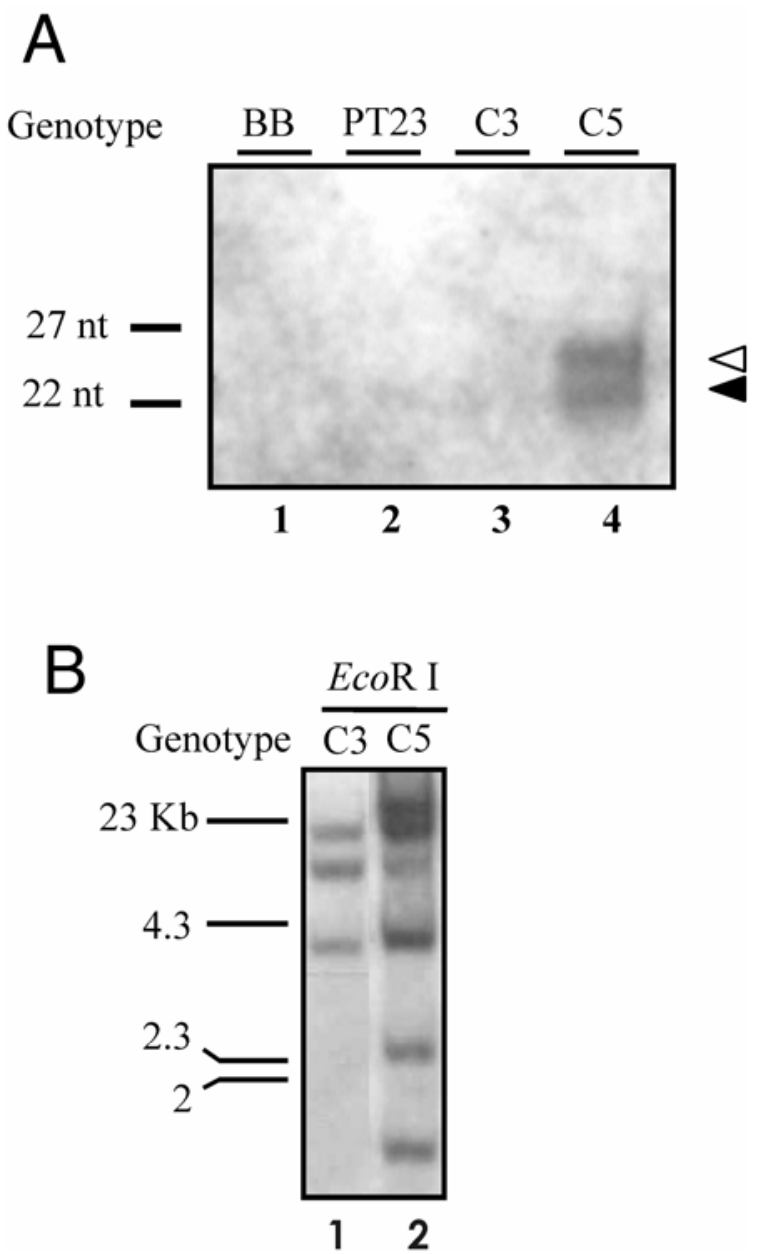

Fig. 1. A, Short interfering (si)RNA production in healthy plum (Prunus domestica L.) leaves. RNA gel blot analysis for detection of siRNAs. Nucleic acid preparation from untransformed 'Bluebyrd' (BB) and transgenic (PT23, C3, and C5) plum leaves were separated on a $20 \%$ denaturing polyacrylamide gel and were hybridized with radioactive DNA probes corresponding to both strands of the full length of the Plum pox virus (PPV) coat protein sequence (Scorza et al. 1994). Positions of the 22- and 27-nt DNA markers are at the left. Black arrow: short 22-nt siRNA. Open arrow: long 25- to 26-nt siRNA. B, DNA gel blot analysis of transgenic plums $\mathrm{C} 3$ and $\mathrm{C} 5$ containing the coat protein of PPV. The EcoRI digests demonstrate that both $\mathrm{C} 3$ and $\mathrm{C} 5$ have multiple bands representing unique insertions. 
PPV CP sequence, and untransformed Prunus plants inoculated with PPV also produced siRNA specific to the PPV CP gene several months following inoculation (Figs. 4 and 5A). This suggests that PTGS is involved as a natural defense mechanism in a woody perennial, as has been reported in herbaceous species (Voinnet 2001). However, in these infected susceptible clones, only the 22-nt siRNA species was present while, in the resistant clone $\mathrm{C} 5$, both siRNA classes ( $22 \mathrm{nt}$ and 25 to $26 \mathrm{nt}$ ) were detected, indicating that these two classes of siRNAs result from different activities.

When hybridized with a probe specific to the PPV Pl gene (Fig. 5B), the same pattern of virus degradation products and siRNA (corresponding to the 22-nt class size) were detected in extracts of susceptible clones (Fig. 5A and B, lanes 1 and 3). In contrast, PPV P1 sequence in C5 leaf extracts (Fig. 5B, lane 5) was below detection limits and neither virus degradation nor siRNAs were detected. Similar patterns were observed when probed with PPV HC-Pro sequences (data not presented). This confirmed that $\mathrm{C} 5$ was virus-free and that the transgene is the source of the long class of siRNA inducing the resistant phenotype of clone $\mathrm{C} 5$.

In order to confirm that the presence of siRNA in C5 leads to PPV resistance, we inoculated 1-week-old C5, C3, and untransformed 'Bluebyrd' seedlings, using viruliferous aphids.
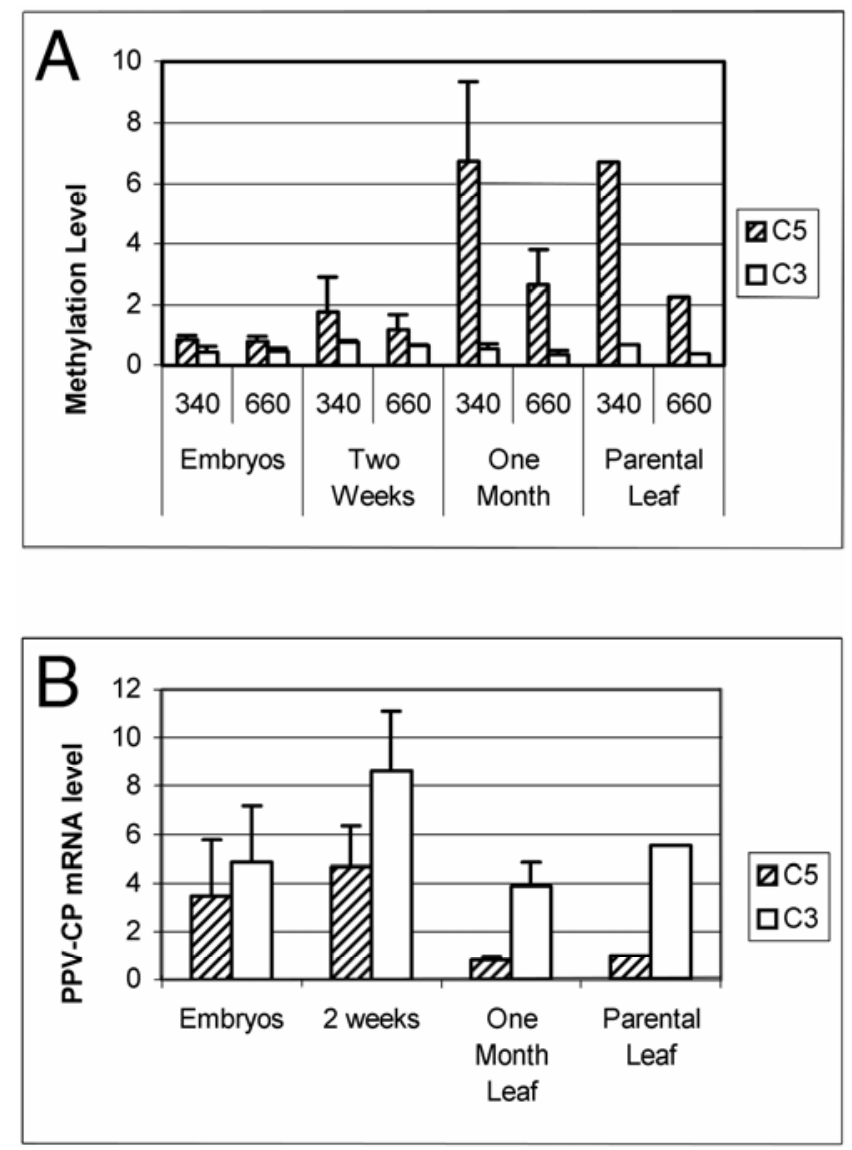

Fig. 2. Relative quantification of methylation and mRNA by real-time polymerase chain reaction (PCR) and reverse transcriptase (RT)-PCR (TaqMan). A, The $\mathrm{X}$ axis indicates the different developmental stages evaluated for methylation; sites 340 and 660 were methylation-sensitive sites (Sau3AI) in the Plum pox virus coat protein (PPV CP) sequence. B, The $\mathrm{X}$ axis indicates the different developmental stages evaluated. Values represent levels of amplification obtained from the threshold cycle number $\left(\mathrm{C}_{\mathrm{t}}\right)$. There is a linear relationship between the amplification value and the amount of amplifiable starting material. The greater the level of DNA methylation or of RNA expression, the higher the amplification value. Values are the average of at least three independent experiments.
Seven days after inoculation, infection was evaluated by realtime fluorescent reverse transcriptase (RT)-PCR. All 17 C5 seedlings tested negative, while three of seven $\mathrm{C} 3$ and four of six 'Bluebyrd' were positive for PPV (data not presented). These observations confirmed the hypothesis that production of the long class of siRNA and PPV resistance are linked. No siRNA were observed in RNA extracts from susceptible plum leaves 7 days postinoculation, indicating that the natural defense based on RNA silencing was not yet functioning (Fig. 3, lanes 1 and 2). In contrast, C5 seedlings at the same developmental stage displayed the two classes of siRNAs (Fig. 3, lane 3) as found in the mature plant.

\section{DISCUSSION}

The present study was undertaken to better understand the plant-virus interaction involved in PPV resistance of a woody perennial fruit tree transformed with the PPV CP gene (Scorza et al. 1994). Investigation of an herbaceous model indicated that transgene silencing was not meiotically stable (Guo et al. 1999). In this report, we show that in early development stages, embryo and 2 weeks postgermination, characteristics of PTGS in C5 are altered, with low levels of methylation and high levels of PPV CP mRNA in the cytoplasm. These levels are comparable to those in a susceptible transgenic clone. At 1 month postgermination, methylation and PPV CP transcription were at the levels found in the mature C5, indicating that methylation and PPV CP transcription were re-set following meiosis. Conversely, we found that the accumulation of siRNA appeared to remain relatively stable following meiosis in progeny of C5 and was evident in the earliest developmental samples (ungerminated embryos).

We also demonstrated the accumulation of two classes of siRNAs in a virus-resistant transgenic woody perennial and have shown that those siRNAs are constitutively present only in the resistant clone and as early as the mature embryo stage.

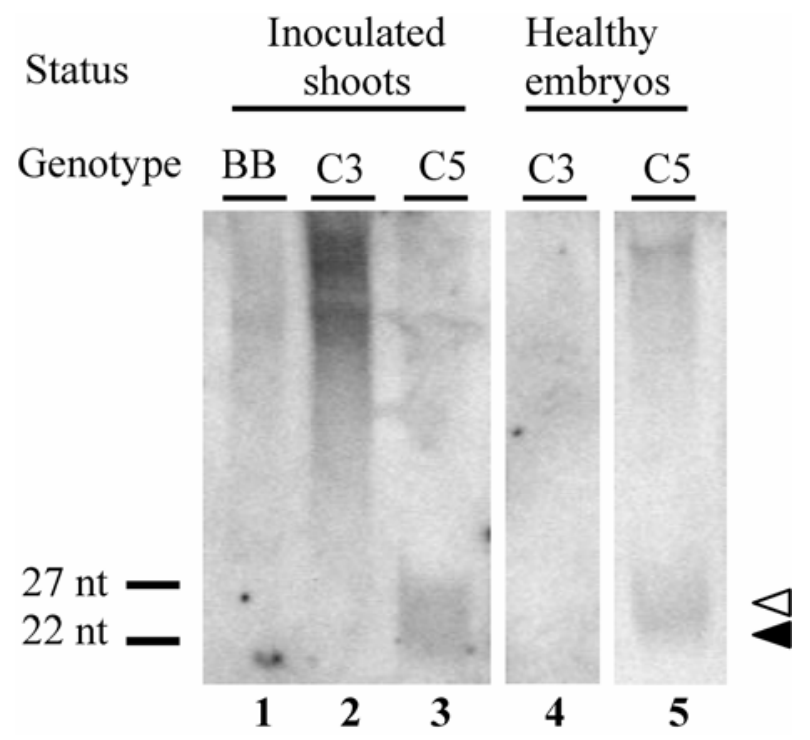

Fig. 3. Short interfering (si)RNA accumulation in early developmental stages in plum (Prunus domestica L.). Healthy embryos (C3 and C5) and inoculated shoots of untransformed 'Bluebyrd' (BB) and transgenic (C3 and C5) plums were analyzed. These shoots were inoculated 7 days postgermination and were analyzed at 14 days. Nucleic acid preparation were separated on a $20 \%$ denaturing polyacrylamide gel and were hybridized with radioactive DNA probes corresponding to both strands of the full length of the Plum pox virus coat protein sequence (Scorza et al. 1994). Positions of the 22- and 27-nt DNA markers are at the left. Black arrow: short 22-nt siRNA. Open arrow: long25- to 26-nt siRNA. 
Two possible explanations are given for this observation. The first is based on the structure of the transgene. C5 possesses a multicopy insert with repeated sequences and aberrant copies (Scorza et al. 2001). Hairpin RNA, produced by self-complementary DNA, has been shown to efficiently silence genes (Wesley et al. 2001). The PPV CP insert in C5 could contain a self-complementary motif and, after transcription, produce dsRNA. The dsRNA could then trigger sequence-specific degradation to produce siRNAs. Over time, these siRNAs could then trigger the PTGS pathway by specifically methylating the transgene sequence and, via the RISC complex, degrade the PPV CP mRNA. A detailed analysis of the transgene insert structure, which is in progress, will help address this first possibility. Alternatively, siRNAs may be supplied to the embryo by the $\mathrm{C} 5$ mother plant. This second possibility may be investigated in the future by testing for siRNAs in transgenic embryos derived from a nontransformed tree using $\mathrm{C} 5$ as a male parent.

The accumulation of different siRNA size classes was the result of different inducers, virus infection, or transgenes. Our results suggest that the short class of siRNA ( $22 \mathrm{nt})$ is part of a natural plant defense mechanism against the virus, as previously proposed (Voinnet et al. 2001). In PPV silencing in plum, short siRNAs covered multiple regions of the PPV genome including the $C P, P l$, and $H C$-Pro genes. The virus seems to act as both inducer and target in this process. Similar observations have been made in peach and chrysanthemum leaves inoculated with Peach latent mosaic viroid and Chrysanthemum chlorotic mottle viroid, respectively (Martinez de Alba et al. 2002), and in pumpkin (Yoo et al. 2004). The short class of siRNA has been proposed to guide the RISC ribonuclease in degrading specific mRNAs in herbaceous plants and is involved in a local silencing (Hamilton et al. 2002). Inoculated susceptible plums produce only the short class of siRNA, and the virus, through high replication, accumulation, and subsequent movement, may then overcome local silencing. We also show that the transgenic plum clone C5, which is highly resistant to PPV, also produces a long ( 25 to $26 \mathrm{nt}$ ) class of siRNA. Long species of siRNA have been associated with specific DNA methylation and systemic silencing (Hamilton et al. 2002). The constitutive production of both short and long siRNAs may induce both local and systemic silencing result-

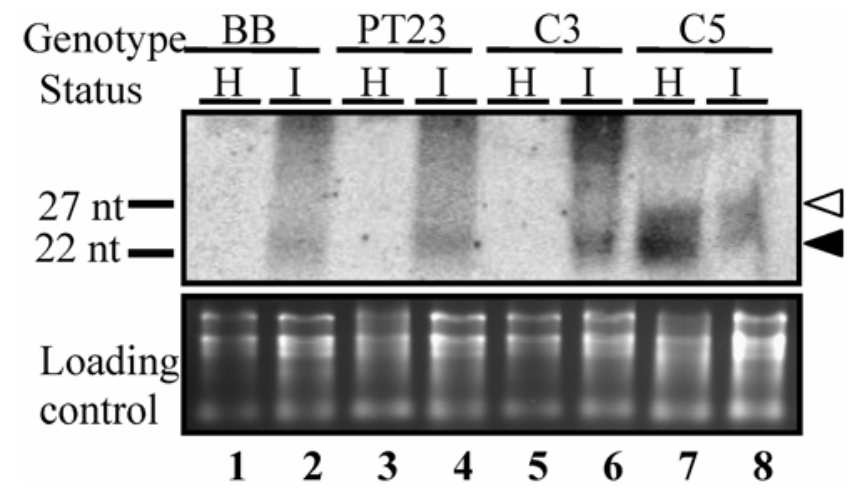

Fig. 4. The effect of Plum pox virus (PPV) inoculation on short interfering (si)RNA accumulation in plum (Prunus domestica L.) leaves. RNA gel blot analysis for detection of siRNAs. Nucleic acid preparation from healthy $(\mathrm{H})$ and inoculated (I) untransformed 'Bluebyrd' (BB) and transgenic (PT23, C3, and C5) plum leaves were separated on a $20 \%$ denaturing polyacrylamide gel and were hybridized with radioactive DNA probes corresponding to both strands of the full length of the PPV coat protein sequence (Scorza et al. 1994). Positions of the 22- and 27-nt DNA markers are at the left. Relative quantification was performed on a $1 \%$ nondenaturing agarose gel, using ethidium bromide staining. Black arrow: short 22-nt siRNA. Open arrow: long 25- to 26-nt siRNA. ing in the lack of detectable virus infection in clone $\mathrm{C} 5$. The long siRNA may also be specifically associated with methylation, since the PPV CP transgene sequence is specifically methylated in $\mathrm{C} 5$, while in $\mathrm{C} 3$, the same sequence does not appear to be methylated in the presence or absence of the virus (Hily et al. 2004; Scorza et al. 2001).

PTGS-based resistance may be overcome by potyvirus HCPro (Anandalakshmi et al. 1998). In model systems utilizing $\beta$ glucuronidase (GUS)- or green fluorescent protein (GFP)-expressing transgene constructs and HC-Pro/GUS or HC-Pro/GFP vectors, HC-Pro has been shown to interact at the PTGS maintenance step by inhibiting degradation of the target mRNA and, consequently, preventing siRNA accumulation (Anandalakshmi et al. 1998; Llave et al. 2000; Mallory et al. 2001). It has also
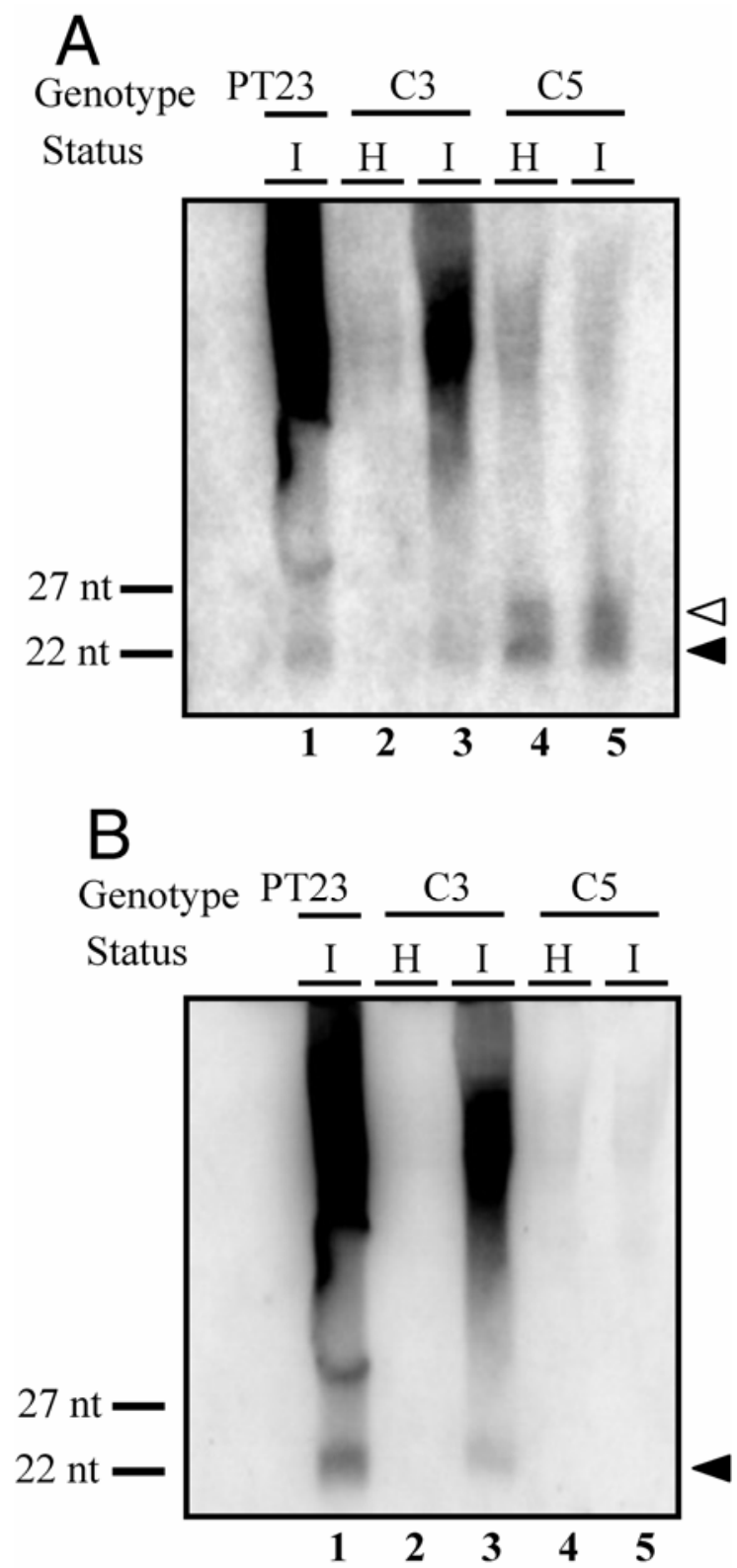

Fig. 5. Accumulation of short interfering (si)RNA corresponding to different regions of the virus in sensitive (PT23 and C3) and resistant (C5) clones. A, RNA blot from healthy $(\mathrm{H})$ and Plum pox virus (PPV)-infected (I) plum leaves separated in a $20 \%$ denaturing polyacrylamide gel, hybridized with a full-length PPV coat protein probe. B, The same membrane as that in A, after stripping and probed with the PPV P1 gene. Positions of the 22- and 27-nt DNA markers are at the left. Black arrow: short 22-nt siRNA. Open arrow: long 25- to 26-nt siRNA. 
been demonstrated that HC-Pro does not interfere with systemic silencing (Mallory et al. 2001). We show in a natural system of virus-host interactions that, while untransformed uninoculated plum plants lack detectable siRNAs, these plants react to PPV inoculation by producing the short species of siRNA with homology to several regions of the PPV genome, including P-1 and HC-Pro. The resistance mounted by the short class of siRNAs is apparently overcome. Our results suggest that the long fragment of siRNA is derived from the virus transgene transcript responsible for methylation and systemic silencing (Hamilton et al. 2002). At this time, there is no evidence that nontransformed plums produce the long class of siRNAs. In the case of C5, a constitutive producer of both the short and long siRNAs, we do not detect a reduction of either siRNA class upon inoculation. The role of PPV HC-Pro in the accumulation of siRNA in both untransformed plants and the transgenic C5 plum clone is under investigation.

Combined with previous reports (Ravelonandro et al. 1997; Scorza et al. 1994, 2001), the detection of siRNAs in PPVresistant $\mathrm{C} 5$ plum demonstrates that all components of the PTGS pathway are present. We hypothesize, based on our results, that the long siRNA class is responsible for high levels of virus resistance and, thus, critical for PTGS-based engineered resistance. While the PTGS system appears to function in woody perennials as in herbaceous annual species, the longterm seasonal interactions with the environment, including cold-induced dormancy, and the potential long-term exposure to pathogens through natural root grafting and bud grafting provide opportunities to study PTGS in a unique biological setting.

\section{MATERIALS AND METHODS}

Mature plants, virus strain, and inoculation methods.

PPV-susceptible transgenic clone C3 and PPV-resistant transgenic clone $\mathrm{C5}$, which harbor the $C P$ gene of PPV used in this study were described by Scorza and associates (1994). Controls were plum clone PT23 (Scorza et al. 2001), a tree transformed only with the two marker genes, NPTII and GUS, both in common with $\mathrm{C} 3$ and $\mathrm{C} 5$, and also untransformed susceptible commercial plum cultivar Bluebyrd. Noninoculated plants were grown from bud grafts onto peach seedling rootstocks in a greenhouse at the United States Department of Agriculture (USDA) in Kearneysville, West Virginia. Infected plants were inoculated with PPV M (GenBank accession NC001445). All inoculation studies were performed under containment conditions at USDA Agricultural Research Station FDWSRU (under Animal and Plant Health Inspection Service [APHIS] permit number 15807) (Ft. Detrick, MD, U.S.A.).

Mature plants used for inoculation were produced through bud grafting onto PPV-susceptible, nontransformed peach $(P$. persica) rootstocks. Inoculation with PPV was by grafting test plants with chip buds collected from infected trees of $P$. tomentosa or $P$. persica 'GF305'. Infection was confirmed through observations of symptoms and through enzymelinked immunosorbent assay. Plants in the quarantine greenhouse were subjected to a yearly cycle of 3 months of cold dormancy $\left(4^{\circ} \mathrm{C}\right)$ followed by 9 months of growth at normal greenhouse temperatures $\left(27^{\circ} \mathrm{C}\right)$. Leaf samples (10 to 20 leaves) were collected at random from around each plant and consisted of mature and near-mature leaves. Leaf samples from inoculated plants were collected 2 months post-coldinduced dormancy, when the virus level was expected to be at the maximum in the plant. Leaves were immediately frozen in liquid nitrogen, were lyophilized, and then, were stored at $-80^{\circ} \mathrm{C}$. Three to five plants were tested per genotype per treatment (infected or noninfected).
Embryo, seedlings, virus strain, and inoculation methods.

After harvesting fruits of uninfected C5 and C3 trees grown under field conditions, seeds were extracted from ripe fruits. Fifty seeds of each line were soaked overnight in a solution of 500 ppm $N$-6-benzylaminopurine and $500 \mathrm{ppm}$ gibberellic acid to induce germination. For molecular analyses of embryos, immediately after harvesting fruits, the embryonic axis and one cotyledon per seed were frozen in liquid nitrogen. The other cotyledon from each seed was analyzed to detect GUS transgene activity (Jefferson 1987).

To study the reaction of seedlings to PPV, aphid inoculations were conducted when plantlets were 1 week old by using a modified 'free roaming' method where aphids were allowed to move freely from infected peach 'Lovell' leaves (isolate PPVPENN 3) to test seedlings. Following inoculation, seedlings were sprayed with an insecticide to eliminate the aphids.

\section{DNA isolation, gel blots, and methylation analyses.}

To follow the molecular characteristics of the PPV transgene, DNA was extracted from single embryos whose cotyledons showed a GUS-positive reaction, from germinating plantlets within 2 weeks of planting, from 1-month-old leaf samples, and from maternal midseason leaves of parental trees, as previously described (Scorza et al 1994). DNA $(10 \mu \mathrm{g})$ was digested with EcoRI enzyme according to the manufacturer's instruction (BRL, Gaithersburg, MD, U.S.A.) and was resolved on a $1 \%$ agarose gel. Detection was performed as described by Scorza and associates (1994). DNA blotting confirmed the presence of the PPV CP gene and the restriction enzyme digest pattern typical of the $\mathrm{C} 5$ or $\mathrm{C} 3$ parent.

The remaining DNA was digested with methylation-sensitive restriction enzyme Sau3AI (Promega) as described by Scorza and associates (2001). Quantitative PCR was performed as described by Hily and associates (2004). Data were analyzed using the comparative threshold cycle number $\left(\mathrm{C}_{\mathrm{t}}\right)$ method outlined in the manufacturer's user's bulletin (PE Applied Biosystems, Foster City, CA, U.S.A.).

\section{siRNA and quantitative RT-PCR for mRNA detection.}

Total RNA was extracted using the Purescript kit (Gentra Systems, Inc., Minneapolis, MN, U.S.A.). The lysis buffer was amended with 2\% (wt/vol) PVP-40 (Invitrogen, Carlsbad, CA, U.S.A.), per the manufacturer's recommendation for woody plant RNA isolation. For siRNA detection, samples were redissolved in $50 \%$ formamide. Relative quantification of low-molecular-weight RNA was performed on a $1 \%$ nondenaturing agarose gel, using ethidium bromide staining. Samples (equivalent to $20 \mu \mathrm{g}$ of total RNA, except from single embryo samples) were heat-treated for $4 \mathrm{~min}$ and were placed on ice for $10 \mathrm{~min}$, before loading onto a $0.5 \times$ Tris-borate-EDTA (TBE) polyacrylamide gel (20\%). DNA oligonucleotides specific to PPV $\mathrm{CP}$ sequence ranging from 22 to $27 \mathrm{nt}$ was also loaded onto the gel as size markers. After electrophoresis, the nucleic acids were electroblotted in $0.5 \times \mathrm{TBE}$ buffer to a Hybond Nx membrane (Amersham Biosciences, Buckinghamshire, U.K.) and were fixed by UV irradiation. Hybridization was performed using in vitro synthesized ${ }^{32} \mathrm{P}$-labeled DNA PPV CP probes generated as previously described (Scorza et al. 1994). The same membrane was then probed with either PPV P1- or PPV HC-Pro-specific sequences.

For quantitative RT-PCR analysis of transgene RNA, contaminating DNA was removed using a DNA-free kit (Ambion, Austin, TX, U.S.A.). RT-PCR reactions utilized Taqman Onestep RT-PCR master mix reagents following manufacturer's instructions and were monitored by the ABI7900HT (PE Applied Biosystems). The control primers used for DNA methylation analyses were used as gene-specific RT-PCR primers 
for the PPV $C P$ and GUS genes. Ribosomal RNA 26S sequence was used to develop primers for use as an endogenous calibrator. For detection of the virus in inoculated seedlings, primers and probe specific to the NIb replicase of PPV were used as described by Schneider and associates (2004). Quantitative RT-PCR reaction employed Taqman probes instead of the SYBR Green used in DNA methylation studies. These probes were designed using Primer Express software and were synthesized by PE Applied Biosystems to contain the following sequences:

PPV CP: 6FAM- TGC ACC GGC AGC AAC TAG CCC TAMRA

GUS: 6FAM- CCA CTG GCG GAA GCA ACG CG TAMRA

26S: 6FAM- TGG TTG AAA AGC CAG TGG CGC G TAMRA

Data were analyzed mathematically using relative standard curve methods as in User Bulletin \#2 (PE Applied Biosystems).

\section{ACKNOWLEDGMENTS}

The authors extend their appreciation to O. Voinnet for advice in siRNA detection, to A. M. Callahan and Z. Liu for consultation and assistance in this work, and to W. Schneider for providing infected samples. USDAAPHIS funding for J.-M. Hily is gratefully acknowledged.

\section{LITERATURE CITED}

Anandalakshmi, R., Pruss, G. J., Ge, X., Marathe, R., Mallory, A. C., Smith, T. H., and Vance, V. 1998. A viral suppressor of gene silencing in plants. Proc. Natl. Acad. Sci. U.S.A. 95:13079-13084.

Bennetzen, J. L. 2000. Transposable element contributions to plant gene and genome evolution. Plant Mol. Biol. 42:251-269.

Bernstein, E., Caudy, A. A., Hammond, S. M., and Hannon, G. J. 2001 Role for a bidentate ribonuclease in the initiation step of RNA. Nature 409:363-366.

Elbashir, S. M., Lendeckel, W., and Tuschl, T. 2001. RNA interference is mediated by 21- and 22- nucleotide RNAs. Gene Dev. 15:188-200.

Fire, A., Xu, S., Montgomery, M. K., Kostas, S. A., Driver, S. E., and Mello, C. C. 1998. Potent and specific genetic interference by double stranded RNA in Caenorhabditis elegans. Nature 391:806-811.

Guo, H. S., Lopez-Moya, J. J., and Garcia, J. A. 1999. Mitotic stability of infection-induced resistance to Plum pox potyvirus associated with transgene silencing and DNA methylation. Mol. Plant-Microbe Interact. 12:103-111.

Hamilton, A. J., and Baulcombe, D. C. 1999. A species of small antisense RNA in posttranscriptional gene silencing in plants. Science 286:950952

Hamilton, A., Voinnet, O., Chappel, I., Baulcombe, D. 2002. Two classes of short interfering RNA in RNA silencing. EMBO (Eur. Mol. Biol. Organ.) J. 21:4671-4679.

Hammond, S. M., Bernstein, E., Beach, D., and Hannon G. J. 2000 An RNA-directed nuclease mediates post-transcriptional gene silencing in Drosophila cells. Nature 404:293-296.

Hannon, G. J. 2002. RNA interference. Nature 418:244-251.

Hily, J. M., Scorza, R., Malinowski, T., Zawadzka, B., and Ravelonandro, M. 2004. Stability of gene-silencing based resistance to Plum pox virus under field conditions. Transgenic Res.13:427-436.

Hutvagner, G., and Zamore P. D. 2002. A microRNA in multiple-turnover RNAi enzyme complex. Science 297:2056-2060.

Ingelbrecht, I. L., Van Houdt, H., Van Montagu, M., and Depicker, A 1994. Post-transcriptional silencing of reporter transgenes in tobacco correlates with DNA methylation. Proc. Natl. Acad. Sci. U.S.A. 91:10502-10506.

Jefferson, R. A. 1987. Assaying chimeric genes in plants: The GUS gene fusion system. Plant Mol. Biol. Rept. 5:387-405.

Kooter, J. M., Matzke, M. A., and Meyer P. 1999. Listening to the silent genes: Transgene silencing, gene regulation and pathogen control. Trends Plant Sci. 4:340-347.

Lipardi, C., Wei, Q., and Paterson, B. M. 2001. RNAi as random degradative PCR: siRNA primers convert mRNA into dsRNAs that are degraded to generate new siRNAs. Cell 107:297-307.

Llave, C., Kassachau, K. D., and Carrington, J. C. 2000. Virus-encoded suppressor of posttranscriptional gene silencing targets a maintenance step in the silencing pathway. Proc. Natl. Acad. Sci. U.S.A. 97:1340113406.

Llave, C., Kasschau, K. D., Rector M. A., and Carrington, J. C. 2002. Endogenous and silencing-associated small RNAs in plants. Plant Cell 14:1605-1619.

Mallory, A. C., Ely, L., Smith, T. H., Marathe, R., Anandalakshmi, R., Fagard, M., Vaucheret, H., Pruss, G., Bowman, L., and Vance, V. B. 2001. HC-Pro suppression of transgene silencing eliminates the small RNAs but not transgene methylation or the mobile signal. Plant Cell 13:571-583.

Martinez de Alba, A. E., Flores, R., and Hernandez C. 2002. Two chloroplastic viroids induce the accumulation of small RNAs associated with posttranscriptional gene silencing. J. Virol. 76:13094-13096.

Matzke, M. A., Matzke A. J., Pruss, G. J., and Vance, V. B. 2001. RNAbased silencing strategies in plants. Curr. Opin. Genet. Dev. 11:221227.

Ravelonandro, M., Scorza. R., Bachelier., J. C., Labonne, G., Levy, L., Damsteegt, V., Callahan, A. M., and Dunez, J. 1997. Resistance of transgenic Prunus domestica to plum pox virus infection. Plant Dis. 81:1231-1235.

Ravelonandro, M., Dunez, J., Scorza, R., and Labonne, G. 1998. Challenging transgenic plums expressing potyvirus coat protein genes with viruliferous aphids. Acta Hort. 472:413-420.

Schneider, W. L., Sherman, D. J., Stone, A. L., Damsteegt, V. D., and Frederick, R. D. 2004. Specific detection and quantification of Plum pox virus by real-time fluorescent reverse transcription-PCR. J. Virol. Methods 120:97-105.

Scorza, R., Ravelonandro, M., Callahan, A. M., Cordts, J. M., Fuchs, M., Dunez, J., and Gonsalves, D. 1994. Transgenic plums (Prunus domestica L.) express the plum pox virus coat protein gene. Plant Cell Rep. 14:18-22.

Scorza, R., Callahan, A. M., Levy, L., Damsteegt, V., and Ravelonandro, M. 1998. Transferring potyvirus coat protein genes through hybridization of transgenic plants to produce plum pox virus resistant plums (Prunus domestica L.). Acta Hort. 472:421-427.

Scorza, R., Callahan, A., Levy, L., Damsteegt, V., Webb, K., and Ravelonandro, M. 2001. Post-transcriptional gene silencing in plum pox virus resistant transgenic European plum containing the plum pox potyvirus coat protein gene. Transgenic Res. 10:201-209.

Vaucheret, H., Beclin, C., and Fagard M. 2001. Post-transcriptional gene silencing in plants. J. Cell. Sci. 114:3083-3091.

Voinnet, O. 2001. RNA silencing as a plant immune system against viruses. Trends Genet. 17:449-459.

Waterhouse, P. M., Wang, M. B., and Lough, T. 2001. Gene silencing as an adaptative defense against viruses. Nature 411:834-842.

Wesley, S. V., Helliwell, C. A., Smith, N. A., Wang, M. B., Rouse, D. T., Liu, Q., Gooding, P. S., Singh, S. P., Abbott, D., Stoutjesdijk, P. A., Robinson, S. P., Gleave, A. P., Green, A. G., and Waterhouse, P. M. 2001. Construct design for efficient, effective and high throughput gene silencing in plants. Plant J. 27:581-590.

Wianny, F., and Zernicka-Goetz, M. 2000. Specific interference with gene function by double-stranded RNA in early mouse development. Nature Cell Biol. 2:70-75.

Yoo, B. C., Kragler, F., Varkonyi-Gasic, E., Haywood, V., Archer-Evans, S., Lee, Y. M., Lough, T. J., and Lucas, W. J. 2004. A systemic small RNA silencing system in plants. Plant Cell 16:1979-2000. 